\title{
Long Distance Communication Using Localized Optical Soliton via Entangled Photon
}

\author{
I. S. Amiri ${ }^{1}$, D. Gifany ${ }^{2}$, J. Ali ${ }^{1}$ \\ ${ }^{1}$ Institute of Advanced Photonics Science, Nanotechnology Research Alliance, Universiti \\ Teknologi Malaysia (UTM), 81300 Johor Bahru, Malaysia \\ ${ }^{2}$ Faculty of Engineering and Technology, Multimedia University (MMU), Melaka, Malaysia
}

\begin{abstract}
A system of microring resonators (MRRs) is presented to generation entangled photon. Different time slot for continuous variable quantum key distribution (CVQKD) use is applicable in optical wireless link. Chaotic behavior of a soliton pulse within the device can be presented respect to the Kerr nonlinear type of light in the MRR devices. Continuous spatial and temporal signals are generated spreading over the spectrum. The $C V Q K D$ is formed using the localized spatial soliton pulse. Here localized temporal soliton with FWHM and FSR of $0.2 \mathrm{ps}$ and $0.58 \mathrm{~ns}$ is obtained respectively. The spatial soliton pulse has a FWHM of $80 \mathrm{pm}$. Transmission of soliton pulse with FWHM of 1.5 ps is simulated along the long distance fiber optics where the polarized photons are formed incorporating with the polarization control unit into the MRRs, which allows different time slot entangled photons to be randomly formed.
\end{abstract}

Keywords: Microring Resonator, Spatial and Temporal Soliton, continuous variable quantum distribution

\section{INTRODUCTION}

CVQKD can form requires information providing the perfect communication security [1]. Amiri et al. demonstrated that quantum security could be performed via the optical soliton pulses [2]. To generate a spectrum of light over a broad range [3], an optical soliton pulse is recommended as a powerful laser pulse that can be used to generate chaotic filter characteristics when propagating within nonlinear MRRs [4-7]. Using this technique, the capacity of the transmission data [8] can be secured and increased when the chaotic packet switching is employed [9]. This system is used to trap optical solitons in order to generate entangled photon pair required for CVQKD [10-13]. Generation of the localized soliton pulses for CVQKD application is presented. CVQKD system can be implemented within the optical communication [14-17], where the optical links can be set up using the optical soliton, generated by the chaotic signals [18]. Furthermore, the CVQKD can be generated using different time slot entangled photon pairs [19].

\section{THEORETICAL MODELING}

Schematic diagram of the proposed system is shown in Fig. 1. A soliton pulse with 20 ns pulse width, peak power at $500 \mathrm{~mW}$ is input into the system. The suitable ring parameters are used, for instance, ring radii $R_{1}=10 \mu \mathrm{m}, R_{2}=5 \mu \mathrm{m}$, and $R_{3}=2 \mu \mathrm{m}$. In order to make the system associate with the practical device, the selected parameters of the system are fixed to $\lambda_{0}=1555 \mathrm{~nm}, n_{0}=3.34, A_{\text {eff }}=0.50,0.25 \mu \mathrm{m}^{2}$ and $0.12 \mu \mathrm{m}^{2}, \alpha=0.5 \mathrm{dBmm}^{-1}$ and $\gamma=0.1$. The coupling coefficient of the MRR ranged from 0.9 to 0.975 .

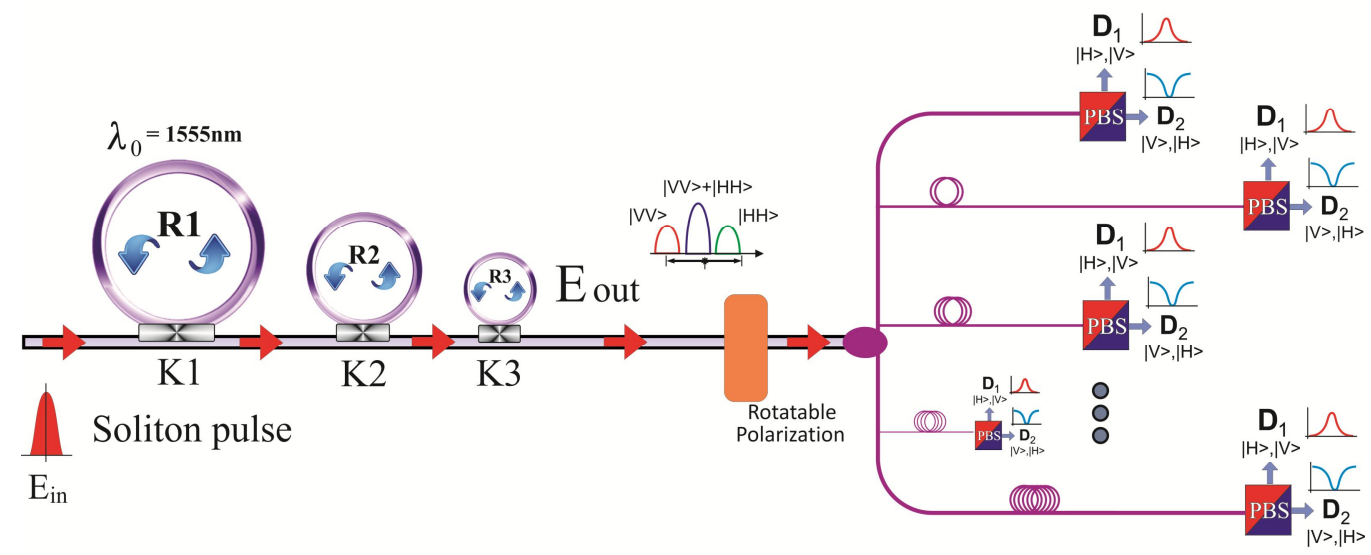

Fig.1: Schematic diagram of a CVQKD with the different time slot entangled photon encoding. PBS, polarizing beam splitter, Ds, detectors, Rs, ring radii and $\kappa \mathrm{s}$, coupling coefficients. 
The soliton pulse is introduced into the proposed system, where the input optical field $\left(E_{i n}\right)$ of the bright soliton pulse can be expressed by [20-22],

$$
E_{\text {in }}=A \sec h\left[\frac{T}{T_{0}}\right] \exp \left[\left(\frac{z}{2 L_{D}}\right)-i \omega_{0} t\right]
$$

$A$ and $z$ are the optical field amplitude and propagation distance, respectively [23]. $T$ is a soliton pulse propagation time in a frame moving at the group velocity [24-26], $T=t-\beta_{1} \times z$ [27], where $\beta_{1}$ and $\beta_{2}$ are the coefficients of the linear and second order terms of the Taylor expansion of the propagation constant [28-32]. $L_{D}=T_{0}^{2} /\left|\beta_{2}\right|$ is the dispersion length of the soliton pulse [33-35]. The carrier frequency of the soliton is $\omega_{0}$ [3637]. This solution describes a pulse that keeps its temporal width invariance as it propagates, and thus is called a temporal soliton [38-40]. When a soliton peak intensity $\left(\left|\beta_{2} / \Gamma T_{0}^{2}\right|\right)$ is given, then $T_{o}$ is known [41-45]. For the soliton pulse in the micro ring device, a balance should be achieved between the dispersion length $\left(L_{\mathrm{D}}\right)$ and the nonlinear length $\left(L_{\mathrm{NL}}=\left(1 / \Gamma \phi_{\mathrm{NL}}\right)\right.$ [46], where $\Gamma=n_{2} \times k_{0}$, is the length scale over which disperse or nonlinear effects makes the beam becomes wider or narrower [47-50]. For a soliton pulse, there is a balance between dispersion and nonlinear lengths, hence $L_{\mathrm{D}}=L_{\mathrm{NL}}$ [51-53]. When light propagates within the nonlinear medium, the refractive index $(n)$ of light within the medium is given by [54-57]

$$
n=n_{0}+n_{2} I=n_{0}+\left(\frac{n_{2}}{A_{e f f}}\right) P
$$

where $n_{0}$ and $n_{2}$ are the linear and nonlinear refractive indexes, respectively [58-62]. $I$ and $P$ are the optical intensity and optical power, respectively [63-65]. The effective mode core area of the device is given by $A_{\text {eff }}$ [66]. For the MRR, the effective mode core areas range from 0.50 to $0.12 \mu \mathrm{m}^{2}$ [67-68]. When a soliton pulse is input and propagated within a MRR as shown in Fig. 1, the resonant output is formed, thus, the normalized output of the light field is the ratio between the output and input fields $E_{\text {out }}(\mathrm{t})$ and $E_{\text {in }}(\mathrm{t})$ in each round-trip, which can be expressed by [69-72]

$$
\left|\frac{E_{\text {out }}(t)}{E_{\text {in }}(t)}\right|^{2}=(1-\gamma)\left[1-\frac{\left(1-(1-\gamma) x^{2}\right) \kappa}{(1-x \sqrt{1-\gamma} \sqrt{1-\kappa})^{2}+4 x \sqrt{1-\gamma} \sqrt{1-\kappa} \sin ^{2}\left(\frac{\phi}{2}\right)}\right]
$$

$\kappa$ is the coupling coefficient [73], and $x=\exp (-\alpha L / 2)$ represents a round-trip loss coefficient [74], $\Phi_{0}=k L n_{0}$ and $\Phi_{\mathrm{NL}}=k L n_{2}\left|E_{\text {in }}\right|^{2}$ are the linear and nonlinear phase shifts [75], $k=2 \pi / \lambda$ is the wave propagation number in a vacuum [76]. Where $L$ and $\alpha$ are the waveguide length and linear absorption coefficient, respectively [77]. In this work, the iterative method is introduced to obtain the results as shown in equation (3), similarly, when the output field is connected and input into the other ring resonators [78].

\section{RESULT AND DISCUSSION}

Large bandwidth within the MRRs device can be generated by using a soliton pulse input shown in Fig. 1 , where the required signals can be generated and perform secure communication network. The nonlinear refractive index is $n_{2}=2.5 \times 10^{-17} \mathrm{~m}^{2} / \mathrm{W}$. In this case, the wave guided loss used is $0.5 \mathrm{dBmm}^{-1}$. From Fig. 2 , the signal is chopped (sliced) into a smaller signal spreading over the spectrum, which shows that the large bandwidth is formed within the first MRR. Compress bandwidth is obtained within the ring $R_{2}$. The amplified gain is obtained within a microring device (i.e. ring $R_{3}$ ). Temporal soliton is formed and trapped by using the constant gain condition. The attenuation of the optical power within a microring device is required in order to keep the constant output gain, where the next round input power is attenuated and kept the same level with the $R_{2}$ output. Here $R_{1}=10 \mu \mathrm{m}, \kappa_{1}=0.95, A_{\text {eff } 1}=50 \mu \mathrm{m}^{2}, R_{2}=5 \mu \mathrm{m}, \kappa_{2}=0.975, A_{\text {eff } 2}=25 \mu \mathrm{m}^{2}, R_{3}=2.5 \mu \mathrm{m}, \kappa_{3}=0.975$, $A_{\text {eff } 3}=0.1 \mu \mathrm{m}^{2}$. The total round trip is 40000 and the central wavelength has been selected to $\lambda=1.55 \mu \mathrm{m}$. 

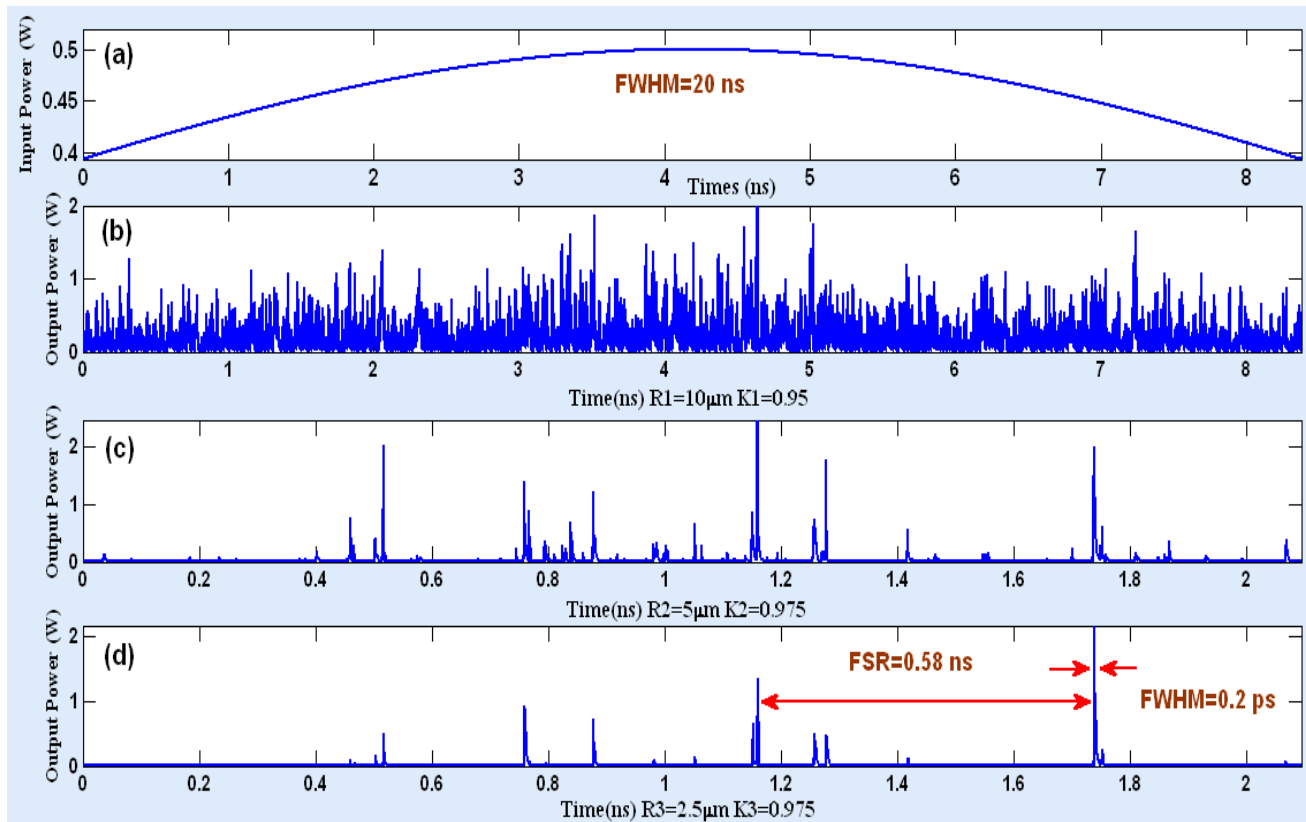

Fig. 2: Results obtained when temporal soliton is localized within a microring device with 40,000 roundtrips where (a): Input bright soliton, (b): Output signal from $R_{1}$, (c): Output signal from $R_{2}$, (d): Output signal from $R_{3}$ with FWHM and FSR of 0.2 ps and 0.58 ns respectively

Similarly, the spatial soliton is obtained as shown in Fig. 3. Here $R_{1}=10 \mu \mathrm{m}, \kappa_{1}=0.975, A_{\mathrm{eff} 1}=50 \mu \mathrm{m}^{2}$, $R_{2}=5 \mu \mathrm{m}, \kappa_{2}=0.975, A_{\text {eff } 2}=25 \mu \mathrm{m}^{2}, R_{3}=4 \mu \mathrm{m}, \kappa_{3}=0.975, A_{\text {eff }}=0.1 \mu \mathrm{m}^{2}$. The central wavelength has been selected to $\lambda=1.525 \mu \mathrm{m}$.
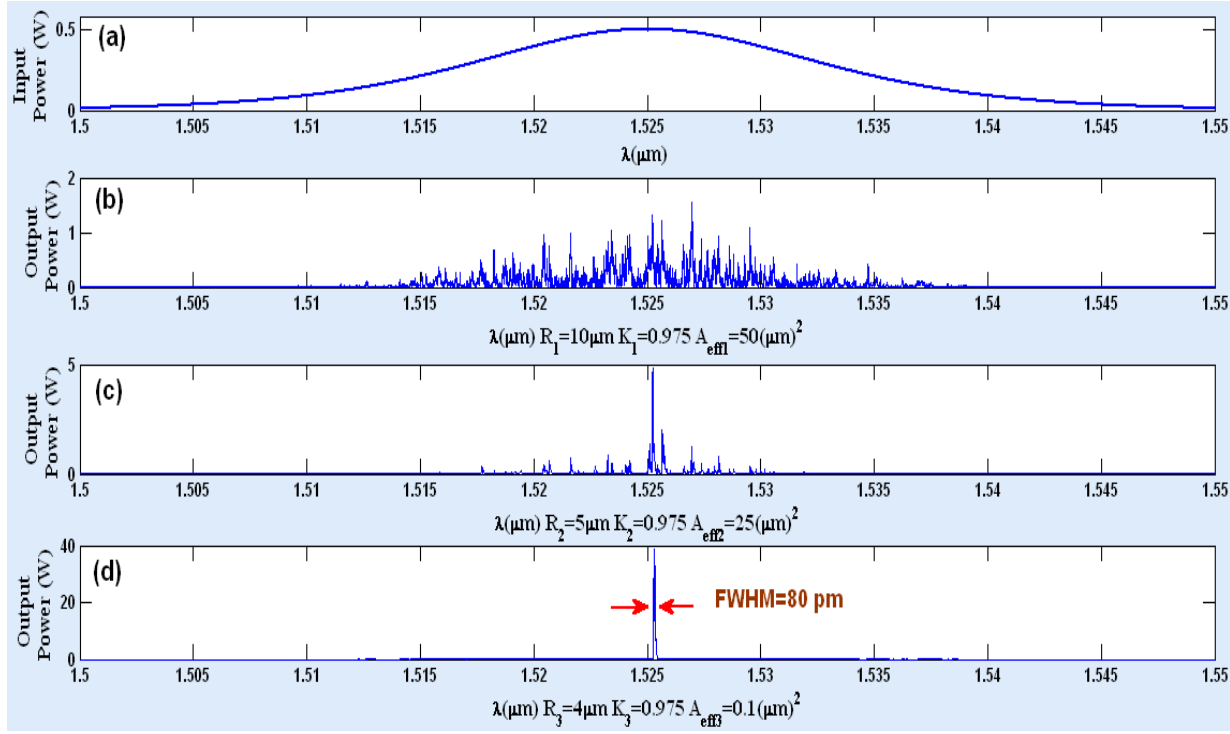

Fig.3: Results obtained when a spatial soliton is localized within a microring device with 40,000 roundtrips, where (a): input bright soliton, (b): output signal from $R_{1}$, (c): output signal from $R_{2}$, (d): output signal from $R_{3}$ with FWHM of $80 \mathrm{pm}$

Soliton pulse with FWHM=1.5 ps and $10 \mathrm{pm}$ can be propagated along long distance fiber optics with nonlinear refractive index of $n_{2}=2.6 \times 10^{-20} \mathrm{~m}^{2} / \mathrm{W}$ and attenuation coefficient of $\alpha=0.4 \mathrm{~dB} / \mathrm{km}$. The simulation results of the transmission through a length of $60 \mathrm{~km}$ and $80 \mathrm{~km}$ are presented shown in Figs. 4 and 5 respectively. 

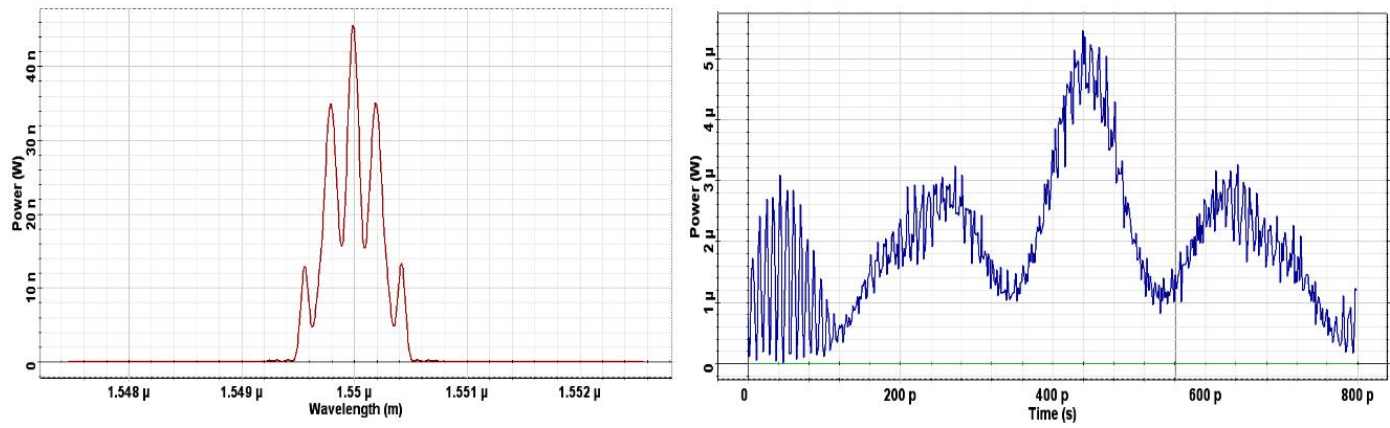

Fig.4: Results obtained when soliton is transmitting along long fiber distance $60 \mathrm{~km}$
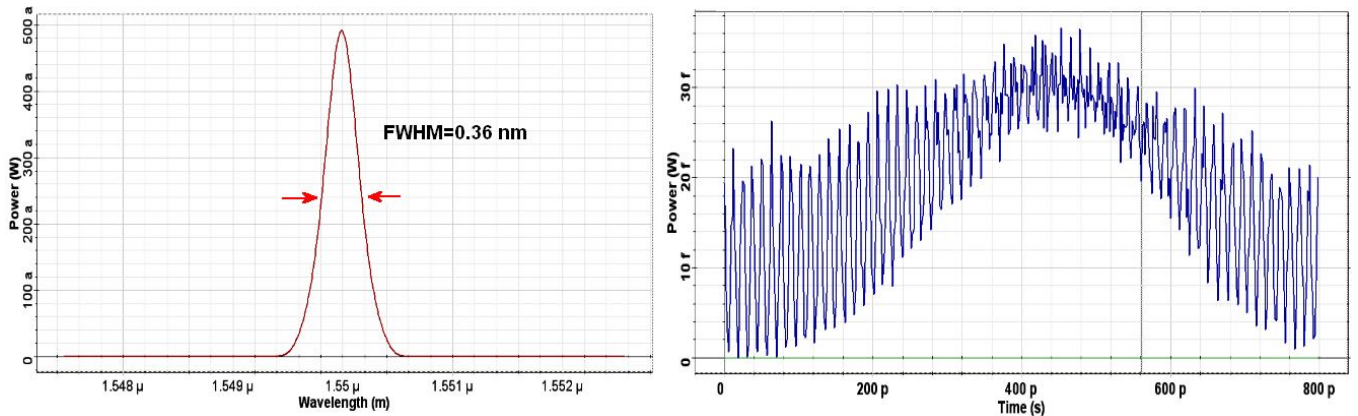

Fig.5: Results obtained when soliton is transmitting along long fiber distance $80 \mathrm{~km}$

The continuous variable of photon can be generated within the proposed system, where each pair of the possible polarization entangled photons is formed within different time frames by using the polarization control unit as shown in Fig. 1, thus they can be represented by the four polarization orientation angles as $\left[0^{\circ}, 90^{\circ}\right]$ and $\left[135^{\circ}, 180^{\circ}\right][79-80]$. They can be formed by using the optical component called the polarization rotatable device and PBS [81]. Using this system, we assume that the polarized entangle photon can be performed by applying the proposed arrangement where each pair of the transmitted entangled photon pair (qubits) with different time slot $\left(t_{1}, t_{2}, t_{3}, \ldots, t_{n}\right)$ can randomly form the entangled pairs [82-83]. Here we introduce the technique that is used to generate the qubits as shown in Fig. 1 [84-85]. A polarization coupler (i.e. last ring, $R_{3}$ ) that separates the basic vertical and horizontal polarization states corresponds to an optical switch between the short and the long pulses [86]. We assume those horizontally polarized pulses with a temporal separation of $\Delta t$. The coherence time of the consecutive pulses is larger than $\Delta t$. Then the following state at time $t_{1}$ is created by equation (4) [87].

$\left|\Phi>_{\mathrm{p}}=\right| 1, \mathrm{H}>_{\mathrm{s}}\left|1, \mathrm{H}>_{\mathrm{i}}+\right| 2, \mathrm{H}>_{\mathrm{s}} \mid 2, \mathrm{H}>_{\mathrm{i}}$

In the expression $|\mathrm{k}, \mathrm{H}\rangle, \mathrm{k}$ is defined as the number of time slots (1 or 2$)$, where it denotes the state of polarization [horizontal $|\mathrm{H}\rangle$ or vertical $|\mathrm{V}\rangle$ ]. The subscript identifies whether the state is the signal $(s)$ or the idler $(i)$ state with considering the assumption that an amplitude term is common to all product states mentioned in the equation (4). We will use the same assumption in subsequent equations in this paper. This two-photon state with $|\mathrm{H}\rangle$ polarization shown by equation (4) is input into the orthogonal polarization-delay circuit shown schematically in Fig. 1. The delay circuit consists of a coupler and the difference between the round-trip times of the MRR, which is equal to $\Delta t$. The microring is tilted by changing the round trip of the ring is converted into $|V\rangle$ at the delay circuit output. That is the delay circuits convert

$\mathrm{r}\left|\mathrm{k}, \mathrm{H}>+\mathrm{t}_{2} \exp (\mathrm{i} \Phi)\right| \mathrm{k}+1, \mathrm{~V}>+\mathrm{rt}_{2} \exp \left(\mathrm{i}_{2} \Phi\right)\left|\mathrm{k}+2, \mathrm{H}>+\mathrm{r}_{2} \mathrm{t}_{2} \exp \left(\mathrm{i}_{3} \Phi\right)\right| \mathrm{k}+3, \mathrm{~V}>$

Where $t$ and $r$ is the amplitude transmittances to cross and bar ports in a coupler. Then equation (4) is converted into the polarized state by the delay circuit as

$$
\begin{aligned}
& \mid \Phi>=\left[\left|1, \mathrm{H}>_{\mathrm{s}}+\exp \left(\mathrm{i} \Phi_{\mathrm{s}}\right)\right| 2, \mathrm{~V}>_{\mathrm{s}}\right] \times\left[\left|1, \mathrm{H}>_{\mathrm{i}}+\exp \left(\mathrm{i} \Phi_{\mathrm{i}}\right)\right| 2, \mathrm{~V}>_{\mathrm{i}}\right] \\
& +\left[\left|2, \mathrm{H}>_{\mathrm{s}}+\exp \left(\mathrm{i} \Phi_{\mathrm{s}}\right)\right| 3, \mathrm{~V}>_{\mathrm{s}} \times\left[\left|2, \mathrm{H}>_{\mathrm{i}}+\exp \left(\mathrm{i} \Phi_{\mathrm{i}}\right)\right| 2, \mathrm{~V}>_{\mathrm{i}}\right]=\right. \\
& {\left[\left|1, \mathrm{H}>_{\mathrm{s}}\right| 1, \mathrm{H}>_{\mathrm{i}}+\exp \left(\mathrm{i} \Phi_{\mathrm{i}}\right)\left|1, \mathrm{H}>_{\mathrm{s}}\right| 2, \mathrm{~V}>_{\mathrm{i}}\right]+\exp \left(\mathrm{i} \Phi_{\mathrm{s}}\right)\left|2, \mathrm{~V}>_{\mathrm{s}}\right| 1, \mathrm{H}>_{\mathrm{i}}+} \\
& \exp \left[\mathrm{i}\left(\Phi_{\mathrm{s}}+\Phi_{\mathrm{i}}\right)\right]\left|2, \mathrm{~V}>_{\mathrm{s}}\right| 2, \mathrm{~V}>_{\mathrm{i}}+\left|2, \mathrm{H}>_{\mathrm{s}}\right| 2, \mathrm{H}>_{\mathrm{i}}+\exp \left(\mathrm{i} \Phi_{\mathrm{i}}\right)\left|2, \mathrm{H}>_{\mathrm{s}}\right| 3, \mathrm{~V}>_{\mathrm{i}}+ \\
& \exp \left(\mathrm{i} \Phi_{\mathrm{s}}\right)\left|3, \mathrm{~V}>_{\mathrm{s}}\right| 2, \mathrm{H}>_{\mathrm{i}}+\exp \left[\mathrm{i}\left(\Phi_{\mathrm{s}}+\Phi_{\mathrm{i}}\right)\right]\left|3, \mathrm{~V}>_{\mathrm{s}}\right| 3, \mathrm{~V}>_{\mathrm{i}}
\end{aligned}
$$


Coincidence counts in the second time slot, we can extract the fourth and fifth terms. As a result, we can obtain the following polarization entangled state as

$$
|\Phi>=| 2, \mathrm{H}>_{\mathrm{s}}\left|2, \mathrm{H}>_{\mathrm{i}}+\exp \left[\mathrm{i}\left(\Phi_{\mathrm{s}}+\Phi_{\mathrm{i}}\right)\right]\right| 2, \mathrm{~V}>_{\mathrm{s}} \mid 2, \mathrm{~V}>_{\mathrm{i}}
$$

We assume that the response time of the Kerr effect is much less than the cavity round-trip time. Because of the Kerr nonlinearity of the optical device [88-90], the strong pulses acquire an intensity dependent phase shift during propagation. The interference of light pulses at a coupler introduces the output beam, which is entangled [91-92]. Due to the polarization states of light pulses are changed and converted while circulating in the delay circuit, where the polarization entangled photon pairs can be generated. The entangled photons of the nonlinear ring resonator are separated to be the signal and idler photon probability. The polarization angle adjustment device is applied to investigate the orientation and optical output intensity described by.

\section{CONCLUSION}

An interesting concept in which continuous variable quantum key distribution can be performed using a remarkably simple system was presented. Proposed system consists of a series of nonlinear MRR and NRR devices. Balance between dispersion and nonlinear lengths of the soliton pulse exhibits the self-phase modulation, which introduces the optical output constant, which means that light pulses can be trapped, localized coherently within the nano-waveguide. We have shown that a large bandwidth of the arbitrary soliton pulses can be generated and compressed within a micro waveguide. The chaotic signal generation using a soliton pulse in the nonlinear MRRs has been presented. The selected light pulse can be localized and used to perform the secure communication network. Localized spatial and temporal soliton pulse propagates along long distance communication where it can be used to generate entangled photon pair providing CVQKD applicable for communication networks. We have analyzed the entangled photon generated by chaotic signals in the series MRR devices. The classical information and security code can be formed by using the temporal and spatial soliton pulses, respectively.

\section{ACKNOWLEDGEMENTS}

I. S. Amiri would like to thank the Institute of Advanced Photonics Science, Nanotechnology Research Alliance, Universiti Teknologi Malaysia (UTM).

\section{REFERENCES}

[1] I. S. Amiri, M. H. Khanmirzaei, M. Kouhnavard, P. P. Yupapin, and J. Ali, Quantum Entanglement using Multi Dark Soliton Correlation for Multivariable Quantum Router, in Quantum Entanglement A. M. Moran, Ed., New York: Nova Science Publisher, 2012.

[2] I. S. Amiri, A. Nikoukar, and J. Ali, Quantum Information Generation Using Optical Potential Well, presented at the Network Technologies \& Communications (NTC) Conference, Singapore, 2010-2011.

[3] A. Afroozeh, I. S. Amiri, M. Bahadoran, J. Ali, and P. P. Yupapin, Simulation of Soliton Amplification in Micro Ring Resonator for Optical Communication, Jurnal Teknologi (Sciences and Engineering), 55, 2012, 271-277.

[4] A. Afroozeh, I. S. Amiri, M. Kouhnavard, M. Jalil, J. Ali, and P. Yupapin, Optical dark and bright soliton generation and amplification, in Enabling Science and Nanotechnology (ESciNano) Conference Malaysia, 2010, 259-263.

[5] A. Afroozeh, I. S. Amiri, M. Kouhnavard, M. Bahadoran, M. A. Jalil, J. Ali, and P. P. Yupapin, Optical Memory Time Using Multi Bright Soliton, presented at the International Conference on Experimental Mechanics (ICEM) Kuala Lumpur, Malaysia, 2010.

[6] J. Ali, H. Nur, S. Lee, A. Afroozeh, I. Amiri, M. Jalil, A. Mohamad, and P. Yupapin, Short and millimeter optical soliton generation using dark and bright soliton, presented at the AMN-APLOC International Conference, Wuhan, China, 2010.

[7] M. Kouhnavard, A. Afroozeh, M. A. Jalil, I. S. Amiri, J. Ali, and P. P. Yupapin, Soliton Signals and the Effect of Coupling Coefficient in MRR Systems, in Faculty of Science Postgraduate Conference (FSPGC), Universiti Teknologi Malaysia, 2010.

[8] P. P. Yupapin, M. A. Jalil, I. S. Amiri, I. Naim, and J. Ali, New Communication Bands Generated by Using a Soliton Pulse within a Resonator System, Circuits and Systems, 1(2), 2010, 71-75.

[9] J. Ali, M. Roslan, M. Jalil, I. Amiri, A. Afroozeh, I. Nawi, and P. Yupapin, DWDM enhancement in micro and nano waveguide, presented at the $A M N-A P L O C$ International Conference, Wuhan, China, 2010.

[10] A. Afroozeh, I. S. Amiri, M. Kouhnavard, M. Bahadoran, M. A. Jalil, J. Ali, and P. P. Yupapin, Dark and Bright Soliton trapping using NMRR, presented at the International Conference on Experimental Mechanics (ICEM), Kuala Lumpur, Malaysia, 2010.

[11] J. Ali, M. A. Jalil, I. S. Amiri, A. Afroozeh, M. Kouhnavard, and P. P. Yupapin, Generation of tunable dynamic tweezers using dark-bright collision, presented at the ICAMN, International Conference, Prince Hotel, Kuala Lumpur, Malaysia, 2010.

[12] I. S. Amiri, M. A. Jalil, F. K. Mohamad, N. J. Ridha, J. Ali, and P. P. Yupapin, Storage of Atom/Molecules/Photon Using Optical Potential Wells, presented at the International Conference on Experimental Mechanics (ICEM), Kuala Lumpur, Malaysia, 2010.

[13] J. Ali, I. S. Amiri, M. A. Jalil, M. Hamdi, F. K. Mohamad, N. J. Ridha, and P. P. Yupapin, Trapping spatial and temporal soliton system for entangled photon encoding, presented at the Nanotech Malaysia, International Conference on Enabling Science \& Technology, Kuala Lumpur, Malaysia, 2010.

[14] I. S. Amiri, G. Vahedi, A. Nikoukar, A. Shojaei, J. Ali, and P. Yupapin, Decimal Convertor Application for Optical Wireless Communication by Generating of Dark and Bright Signals of soliton, International Journal of Engineering Research \& Technology (IJERT), 1(5), 2012,

[15] A. A. Shojaei and I. S. Amiri, DSA for Secured Optical Communication, presented at the International Conference for Nanomaterials Synthesis and Characterization (INSC), Kuala Lumpur, Malaysia, 2011. 
[16] A. Afroozeh, M. Bahadoran, I. S. Amiri, A. R. Samavati, J. Ali, and P. P. Yupapin, Fast Light Generation Using Microring Resonators for Optical Communication, presented at the National Science Postgraduate Conference NSPC, Universiti Teknologi Malaysia, 2011.

[17] I. S. Amiri, A. Nikoukar, G. Vahedi, A. Shojaei, J. Ali, and P. Yupapin, Frequency-Wavelength Trapping by Integrated Ring Resonators For Secured Network and Communication Systems, International Journal of Engineering Research \& Technology (IJERT), 1(5), 2012,

[18] I. S. Amiri, R. Ahsan, A. Shahidinejad, J. Ali, and P. P. Yupapin, Characterisation of bifurcation and chaos in silicon microring resonator, IET Communications, 6(16), 2012, 2671-2675.

[19] I. S. Amiri, A. Afroozeh, M. Bahadoran, J. Ali, and P. P. Yupapin, Molecular Transporter System for Qubits Generation, Jurnal Teknologi (Sciences and Engineering), 55, 2012, 155-165.

[20] J. Ali, A. Afroozeh, I. S. Amiri, M. A. Jalil, and P. P. Yupapin, Dark and Bright Soliton trapping using NMRR, presented at the ICEM, Legend Hotel, Kuala Lumpur, Malaysia, 2010.

[21] J. Ali, M. A. Jalil, I. S. Amiri, and P. P. Yupapin, Dark-bright solitons conversion system via an add/drop filter for signal security application, presented at the ICEM, Legend Hotel, Kuala Lumpur, Malaysia, 2010.

[22] J. Ali, I. S. Amiri, M. A. Jalil, F. K. Mohamad, and P. P. Yupapin, Optical dark and bright soliton generation and amplification, presented at the Nanotech Malaysia, International Conference on Enabling Science \& Technology, KLCC, Kuala Lumpur, Malaysia, 2010.

[23] J. Ali, K. Raman, M. Kouhnavard, I. S. Amiri, M. A. Jalil, A. Afroozeh, and P. P. Yupapin, Dark soliton array for communication security, presented at the AMN-APLOC International Conference, Wuhan, China, 2011.

[24] J. Ali, I. Amiri, A. Jalil, A. Kouhnavard, B. Mitatha, and P. Yupapin, Quantum internet via a quantum processor, presented at the International Conference on Photonics (ICP 2010), Langkawi, Malaysia 2010.

[25] J. Ali, M. A. Jalil, I. S. Amiri, and P. P. Yupapin, Fast and slow lights via an add/drop device, presented at the ICEM, Legend Hotel, Kuala Lumpur, Malaysia, 2010.

[26] I. S. Amiri, A. Afroozeh, I. N. Nawi, M. A. Jalil, A. Mohamad, J. Ali, and P. P. Yupapin, Dark Soliton Array for communication security, Procedia Engineering, 82011, 417-422.

[27] A. Afroozeh, M. Kouhnavard, I. S. Amiri, M. A. Jalil, J. Ali, and P. P. Yupapin, Effect of Center Wavelength on MRR Performance, in Faculty of Science Postgraduate Conference (FSPGC), Universiti Teknologi Malaysia, 2010.

[28] A. Afroozeh, I. S. Amiri, J. Ali, and P. P. Yupapin, Determination of Fwhm For Solition Trapping, Jurnal Teknologi (Sciences and Engineering), 55, 2012, 77-83.

[29] J. Ali, A. Afroozeh, I. S. Amiri, M. Hamdi, M. Jalil, M. Kouhnavard, and P. Yupapin, Entangled photon generation and recovery via MRR, presented at the ICAMN, International Conference, , Prince Hotel, Kuala Lumpur, Malaysia, 2010.

[30] J. Ali, I. Amiri, M. Jalil, M. Kouhnavard, A. Afroozeh, I. Naim, and P. Yupapin, Narrow UV pulse generation using MRR and NRR system, presented at the ICAMN, International Conference, Prince Hotel, Kuala Lumpur, Malaysia, 2010.

[31] I. S. Amiri, A. Afroozeh, and M. Bahadoran, Simulation and Analysis of Multisoliton Generation Using a PANDA Ring Resonator System, Chinese Physics Letters, 28, 2011, 104205.

[32] I. S. Amiri, K. Raman, A. Afroozeh, M. A. Jalil, I. N. Nawi, J. Ali, and P. P. Yupapin, Generation of DSA for security application, Procedia Engineering, 8, 2011, 360-365.

[33] J. Ali, A. Afroozeh, I. Amiri, M. Jalil, and P. Yupapin, Wide and narrow signal generation using chaotic wave, presented at the Nanotech Malaysia, International Conference on Enabling Science \& Technology Kuala Lumpur, Malaysia, 2010.

[34] I. S. Amiri, A. Afroozeh, M. Bahadoran, J. Ali, and P. P. Yupapin, Up and Down Link of Soliton for Network Communication, presented at the National Science Postgraduate Conference, NSPC, Malaysia, 2011.

[35] D. Gifany, I. S. Amiri, M. Ranjbar, and J. Ali, Logic Codes Generation and Transmission Using an Encoding-Decoding System, International Journal of Advances in Engineering \& Technology (IJAET), 5(2), 2013, 37-45

[36] I. S. Amiri, A. Shahidinejad, A. Nikoukar, J. Ali, and P. Yupapin, A Study oF Dynamic Optical Tweezers Generation For Communication Networks, International Journal of Advances in Engineering \& Technology (IJAET), 4(2), 2012, 38-45

[37] M. A. Jalil, I. S. Amiri, C. Teeka, J. Ali, and P. P. Yupapin, All-optical Logic XOR/XNOR Gate Operation using Microring and Nanoring Resonators, Global Journal of Physics Express, 1(1), 2011, 15-22.

[38] J. Ali, A. Afroozeh, I. S. Amiri, M. A. Jalil, M. Kouhnavard, and P. P. Yupapin, Generation of continuous optical spectrum by soliton into a nano-waveguide, presented at the ICAMN, International Conference, Prince Hotel, Kuala Lumpur, Malaysia, 2010.

[39] J. Ali, M. Kouhnavard, I. S. Amiri, M. A. Jalil, A. Afroozeh, and P. P. Yupapin, Security confirmation using temporal dark and bright soliton via nonlinear system, presented at the ICAMN, International Conference, Prince Hotel, Kuala Lumpur, Malaysia, 2010 .

[40] J. Ali, K. Kulsirirat, W. Techithdeera, M. A. Jalil, I. S. Amiri, I. Naim, and P. P. Yupapin, Temporal dark soliton behavior within multi-ring resonators, presented at the Nanotech Malaysia, International Conference on Enabling Science \& Technology, Malaysia 2010 .

[41] A. Afroozeh, I. S. Amiri, M. A. Jalil, M. Kouhnavard, J. Ali, and P. P. Yupapin, Multi Soliton Generation for Enhance Optical Communication, Applied Mechanics and Materials, 83, 2011, 136-140.

[42] J. Ali, I. S. Amiri, M. A. Jalil, A. Afroozeh, M. Kouhnavard, and P. Yupapin, Novel system of fast and slow light generation using micro and nano ring resonators, presented at the ICAMN, International Conference, Prince Hotel, Kuala Lumpur, Malaysia, 2010.

[43] J. Ali, M. Aziz, I. Amiri, M. Jalil, A. Afroozeh, I. Nawi, and P. Yupapin, Soliton wavelength division in MRR and NRR Systems, presented at the AMN-APLOC International Conference, Wuhan, China 2010.

[44] I. S. Amiri, M. A. Jalil, F. K. Mohamad, N. J. Ridha, J. Ali, and P. P. Yupapin, Storage of Optical Soliton Wavelengths Using NMRR, presented at the International Conference on Experimental Mechanics (ICEM), Kuala Lumpur, Malaysia, 2010.

[45] M. A. Jalil, I. S. Amiri, M. Kouhnavard, A. Afroozeh, J. Ali, and P. P. Yupapin, Finesse Improvements of Light Pulses within MRR System, in Faculty of Science Postgraduate Conference (FSPGC), Universiti Teknologi Malaysia, 2010.

[46] N. Suwanpayak, S. Songmuang, M. A. Jalil, I. S. Amiri, I. Naim, J. Ali, and P. P. Yupapin, Tunable and storage potential wells using microring resonator system for bio-cell trapping and delivery, in Enabling Science and Nanotechnology (ESciNano) Conference, 2010, 289-291.

[47] J. Ali, I. S. Amiri, M. A. Jalil, A. Afroozeh, M. Kouhnavard, and P. P. Yupapin, Multi-soliton generation and storage for nano optical network using nano ring resonators, presented at the ICAMN, International Conference, Prince Hotel, Kuala Lumpur, Malaysia, 2010.

[48] J. Ali, M. A. Jalil, I. S. Amiri, and P. P. Yupapin, MRR quantum dense coding, presented at the Nanotech Malaysia, International Conference on Enabling Science \& Technology, KLCC, Kuala Lumpur, Malaysia 2010. 
[49] I. S. Amiri, S. Babakhani, G. Vahedi, J. Ali, and P. Yupapin, Dark-Bright Solitons Conversion System for Secured and Long Distance Optical Communication, IOSR Journal of Applied Physics (IOSR-JAP), 2(1), 2012, 43-48.

[50] I. S. Amiri, A. Nikoukar, J. Ali, and P. P. Yupapin, Ultra-Short of Pico and Femtosecond Soliton Laser Pulse Using Microring Resonator for Cancer Cells Treatment, Quantum Matter, 1(2), 2012, 159-165.

[51] J. Ali, M. A. Jalil, I. S. Amiri, and P. P. Yupapin, Effects of MRR parameter on the bifurcation behavior, presented at the Nanotech Malaysia, International Conference on Enabling Science \& Technology, KLCC, Kuala Lumpur, Malaysia 2010.

[52] I. Amiri, J. Ali, and P. Yupapin, Security Enhancement of the Optical Signal Communication using Binary Codes Generated by Optical Tweezers, Chinese Journal of Physics, 2013,

[53] I. S. Amiri, A. Nikoukar, A. Shahidinejad, J. Ali, and P. Yupapin, Generation of discrete frequency and wavelength for secured computer networks system using integrated ring resonators, in Computer and Communication Engineering (ICCCE) Conference, Malaysia, 2012, 775-778.

[54] A. Afroozeh, M. Bahadoran, I. S. Amiri, A. R. Samavati, J. Ali, and P. P. Yupapin, Fast Light Generation Using GaAlAs/GaAs Waveguide, Jurnal Teknologi (Sciences and Engineering), 57, 2012, 17-23.

[55] J. Ali, M. Kouhnavard, I. S. Amiri, A. Afroozeh, M. A. Jalil, I. Naim, and P. P. Yupapin, Localization of soliton pulse using nanowaveguide, presented at the ICAMN, International Conference, Prince Hotel, Kuala Lumpur, Malaysia, 2010.

[56] I. S. Amiri, J. Ali, and P. P. Yupapin, Enhancement of FSR and Finesse Using Add/Drop Filter and PANDA Ring Resonator Systems, International Journal of Modern Physics B, 26(04), 2012,

[57] I. S. Amiri, M. Ranjbar, A. Nikoukar, A. Shahidinejad, J. Ali, and P. Yupapin, Multi optical Soliton generated by PANDA ring resonator for secure network communication, in Computer and Communication Engineering (ICCCE) Conference, Malaysia, 2012, 760-764.

[58] J. Ali, I. Amiri, A. Afroozeh, M. Kouhnavard, M. Jalil, and P. Yupapin, Simultaneous dark and bright soliton trapping using nonlinear MRR and NRR, presented at the ICAMN, International Conference Malaysia, 2010.

[59] J. Ali, M. Kouhnavard, A. Afroozeh, I. S. Amiri, M. A. Jalil, and P. P. Yupapin, Optical bistability in a FORR, presented at the ICEM, Legend Hotel, Kuala Lumpur, Malaysia, 2010.

[60] M. Bahadoran, I. S. Amiri, A. Afroozeh, J. Ali, and P. P. Yupapin, Analytical Vernier Effect for Silicon Panda Ring Resonator, presented at the National Science Postgraduate Conference, NSPC Universiti Teknologi Malaysia, 2011.

[61] A. Nikoukar, I. S. Amiri, and J. Ali, Secured Binary Codes Generation for Computer Network Communication, presented at the Network Technologies \& Communications (NTC) Conference, Singapore, 2010-2011.

[62] N. J. Ridha, F. K. Mohamad, I. S. Amiri, Saktioto, J. Ali, and P. P. Yupapin, Soliton Signals and The Effect of Coupling Coefficient in MRR Systems, presented at the International Conference on Experimental Mechanics (ICEM), Kuala Lumpur, Malaysia, 2010.

[63] J. Ali, M. Jalil, I. Amiri, A. Afroozeh, M. Kouhnavard, I. Naim, and P. Yupapin, Multi-wavelength narrow pulse generation using MRR, presented at the ICAMN, International Conference, Prince Hotel, Kuala Lumpur, Malaysia, 2010.

[64] I. S. Amiri, M. A. Jalil, A. Afroozeh, M. Kouhnavard, J. Ali, and P. P. Yupapin, Controlling Center Wavelength and Free Spectrum Range by MRR Radii, in Faculty of Science Postgraduate Conference (FSPGC), Universiti Teknologi Malaysia, 2010.

[65] M. Kouhnavard, A. Afroozeh, I. S. Amiri, M. A. Jalil, J. Ali, and P. P. Yupapin, New system of Chaotic Signal Generation Using MRR, presented at the International Conference on Experimental Mechanics (ICEM), Kuala Lumpur, Malaysia, 2010.

[66] A. Afroozeh, I. S. Amiri, A. Samavati, J. Ali, and P. Yupapin, THz frequency generation using MRRs for THz imaging, in Enabling Science and Nanotechnology (ESciNano) Conference, Malaysia, 2012, 1-2.

[67] J. Ali, K. Raman, A. Afroozeh, I. S. Amiri, M. A. Jalil, I. N. Nawi, and P. P. Yupapin, Generation of DSA for security application, presented at the 2nd International Science, Social Science, Engineering Energy Conference (I-SEEC 2010), Nakhonphanom, Thailand, 2010.

[68] I. S. Amiri, A. Shahidinejad, A. Nikoukar, M. Ranjbar, J. Ali, and P. P. Yupapin, Digital Binary Codes Transmission via TDMA Networks Communication System Using Dark and Bright Optical Soliton, GSTF Journal on Computing (joc), 2(1), 2012,

[69] J. Ali, A. Afroozeh, M. Hamdi, I. S. Amiri, M. A. Jalil, M. Kouhnavard, and P. Yupapin, Optical bistability behaviour in a doublecoupler ring resonator, presented at the ICAMN, International Conference, Prince Hotel, Kuala Lumpur, Malaysia, 2010.

[70] J. Ali, S. Saktioto, M. Hamdi, and I. S. Amiri, Dynamic silicon dioxide fiber coupling polarized by voltage breakdown, presented at the Nanotech Malaysia, International Conference on Enabling Science \& Technology, KLCC, Kuala Lumpur, Malaysia, 2010.

[71] F. K. Mohamad, N. J. Ridha, I. S. Amiri, J. A. Saktioto, and P. P. Yupapin, Finesse Improvements of Light Pulses within MRR System, presented at the International Conference on Experimental Mechanics (ICEM), Kuala Lumpur, Malaysia, 2010.

[72] S. Saktioto, S. Daud, J. Ali, M. A. Jalil, I. S. Amiri, and P. P. Yupapin, FBG simulation and experimental temperature measurement, presented at the ICEM, Legend Hotel, Kuala Lumpur, Malaysia, 2010.

[73] S. Saktioto, S. Daud, M. A. Jalil, I. S. Amiri, and P. P. Yupapin, FBG sensing system for outdoor temperature measurement, presented at the ICEM, Legend Hotel, Kuala Lumpur, Malaysia, 2010.

[74] J. Ali, I. S. Amiri, M. A. Jalil, M. Hamdi, F. K. Mohamad, N. J. Ridha, and P. P. Yupapin, Proposed molecule transporter system for qubits generation, presented at the Nanotech Malaysia, International Conference on Enabling Science \& Technology, Malaysia 2010.

[75] F. K. Mohamad, N. J. Ridha, I. S. Amiri, J. A. Saktioto, and P. P. Yupapin, Effect of Center Wavelength on MRR Performance, presented at the International Conference on Experimental Mechanics (ICEM), Kuala Lumpur, Malaysia, 2010.

[76] A. Shahidinejad, A. Nikoukar, I. S. Amiri, M. Ranjbar, A. Shojaei, J. Ali, and P. Yupapin, Network system engineering by controlling the chaotic signals using silicon micro ring resonator, in Computer and Communication Engineering (ICCCE) Conference, Malaysia, 2012, 765-769.

[77] C. Tanaram, C. Teeka, R. Jomtarak, P. P. Yupapin, M. A. Jalil, I. S. Amiri, and J. Ali, ASK-to-PSK generation based on nonlinear microring resonators coupled to one MZI arm, Procedia Engineering, 82011, 432-435.

[78] C. Teeka, S. Songmuang, R. Jomtarak, P. P. Yupapin, M. A. Jalil, I. S. Amiri, and J. Ali, ASK to PSK Generation based on Nonlinear Microring Resonators Coupled to One MZI Arm, in International Conference on Enabling Science and Nanotechnology, EsciNano, Kuala Lumpur, Malaysia, 2011, 221-223.

[79] I. S. Amiri, M. Nikmaram, A. Shahidinejad, and J. Ali, Cryptography Scheme of an Optical Switching System Using Pico/Femto Second Soliton Pulse, International Journal of Advances in Engineering \& Technology (IJAET), 5(1), 2012, 176-184.

[80] M. Kouhnavard, I. S. Amiri, M. Jalil, A. Afroozeh, J. Ali, and P. P. Yupapin, QKD via a quantum wavelength router using spatial soliton, in Enabling Science and Nanotechnology (ESciNano) Conference Malaysia, 2010, 210-216.

[81] A. Nikoukar, I. S. Amiri, A. Shahidinejad, A. Shojaei, J. Ali, and P. Yupapin, MRR quantum dense coding for optical wireless communication system using decimal convertor, in Computer and Communication Engineering (ICCCE) Conference, Malaysia, 2012, 770-774. 
[82] J. Ali, M. Kouhnavard, M. A. Jalil, and I. S. Amiri, Quantum signal processing via an optical potential well, presented at the Nanotech Malaysia, International Conference on Enabling Science \& Technology, Kuala Lumpur, Malaysia 2010.

[83] I. S. Amiri, M. H. Khanmirzaei, M. Kouhnavard, and S. Mitatha, Quantum cryptography via a wavelength router for internet security, Piers Proceeding, Cambridge, 2010,

[84] I. S. Amiri, A. Afroozeh, J. Ali, and P. P. Yupapin, Generation Of Quantum Codes Using Up And Down Link Optical Solition, Jurnal Teknologi (Sciences and Engineering), 55, 2012, 97-106.

[85] A. A. Shojaei and I. S. Amiri, Soliton for Radio wave generation, presented at the International Conference for Nanomaterials Synthesis and Characterization (INSC), Kuala Lumpur, Malaysia, 2011.

[86] I. S. Amiri, A. Nikoukar, A. Shahidinejad, M. Ranjbar, J. Ali, and P. P. Yupapin, Generation of Quantum Photon Information Using Extremely Narrow Optical Tweezers for Computer Network Communication, GSTF Journal on Computing (joc), 2(1), 2012,

[87] I. S. Amiri, G. Vahedi, A. Shojaei, A. Nikoukar, J. Ali, and P. P. Yupapin, Secured Transportation of Quantum Codes Using Integrated PANDA-Add/drop and TDMA Systems, International Journal of Engineering Research \& Technology (IJERT), 1(5), 2012 ,

[88] J. Ali, A. Mohamad, I. Nawi, I. Amiri, M. Jalil, A. Afroozeh, and P. Yupapin, Stopping a dark soliton pulse within an NNRR, presented at the AMN-APLOC International Conference, Wuhan, China 2010.

[89] N. J. Ridha, F. K. Mohamad, I. S. Amiri, Saktioto, J. Ali, and P. P. Yupapin, Controlling Center Wavelength and Free Spectrum Range by MRR Radii, presented at the International Conference on Experimental Mechanics (ICEM), Kuala Lumpur, Malaysia, 2010 .

[90] S. Saktioto, M. Hamdi, I. S. Amiri, and J. Ali, Transition of diatomic molecular oscillator process in THz region, presented at the International Conference on Experimental Mechanics (ICEM), Legend Hotel, Kuala Lumpur, Malaysia, 2010.

[91] M. Imran, R. A. Rahman, and I. S. Amiri, Fabrication of Diffractive Optical Element Using Direct Writing CO2 Laser Irradiation, in Faculty of Science Postgraduate Conference (FSPGC), Universiti Teknologi Malaysia, 2010

[92] S. Saktioto, J. Ali, M. Hamdi, and I. Amiri, Calculation and prediction of blood plasma glucose concentration, presented at the ICAMN, International Conference, Prince Hotel, Kuala Lumpur, Malaysia, 2010. 